\title{
Left Renal Vein Compression and Horseshoe Kidney: An Extraordinary Association
}

\author{
Bulent Guvendi $^{\mathrm{a}} \quad$ Hayri Ogul ${ }^{\mathrm{b}}$ \\ a Department of General Surgery, Faculty of Medicine, Kafkas University, Kars, and b Department of Radiology, \\ Faculty of Medicine, Ataturk University, Erzurum, Turkey
}

\section{Key Words}

Renal artery · Vascular anomaly · Horseshoe kidney

\begin{abstract}
Objective: Our aim was to report the importance of an awareness of renal artery variations if surgical procedures are indicated in this region. Presentation and Intervention: A 41-yearold female patient was admitted to our hospital for preoperative staging of the rectum carcinoma. A computed tomography $(C T)$ scan clearly revealed the presence of normally positioned small right and left renal arteries, and a large aberrant renal artery originating from the distal abdominal aorta in a case with a horseshoe kidney (HSK). A multidetector CT angiography was performed using a 256-detector row CT scanner to obtain an image of vascular structures and associated pathologies. Conclusion: In this patient with HSK, the left renal vein compression was unusual and the CT examination provided a good delineation of vascular and urinary tract anom-
\end{abstract} alies.

(c) 2016 S. Karger AG, Basel

\section{Introduction}

Horseshoe kidney (HSK) is a well-known congenital fusion anomaly of the kidney that combines three anatomic abnormalities (renal ectopia, malrotation and vas-

\begin{tabular}{|c|c|}
\hline KARGER & $\begin{array}{l}\text { (c) 2016 S. Karger AG, Basel } \\
1011-7571 / 16 / 0255-0494 \$ 39.50 / 0\end{array}$ \\
\hline $\begin{array}{l}\text { E-Mail karger@karger.com } \\
\text { www.karger.com/mpp }\end{array}$ & $\begin{array}{l}\text { This is an Open Access article licensed under the terms of the } \\
\text { Creative Commons Attribution-NonCommercial 3.0 Un- } \\
\text { ported license (CC BY-NC) (www.karger.com/OA-license), } \\
\text { applicable to the online version of the article only. Distribu- } \\
\text { tion permitted for non-commercial purposes only. }\end{array}$ \\
\hline
\end{tabular}

cular changes) [1-3]. In the HSK, there is a fusion of the lower or upper poles of both kidneys by a parenchymal or fibrous isthmus $[1,3]$. HSK arterial supply has a wide variation. The renal arteries (RAs) usually originate from the abdominal aorta (AA). Alternatively, they can originate from the common iliac and inferior mesenteric arteries [4]. The isthmus is usually supplied by a small vessel originating from the AA. It is rarely supplied by a large aberrant artery. We hereby report an extraordinary association (left renal vein compression and RA anomaly) of the HSK, which, to the best of our knowledge, has not been mentioned before in the literature.

\section{Case Report}

A 41-year-old woman was admitted to our hospital with rectum carcinoma. She had no history of symptoms from the urinary tract. During the preoperative staging, an abdomen computed tomography $(\mathrm{CT})$ scan (256-slice SOMATOM ${ }^{\circledR}$ Definition Flash Multidetector Row CT system; Siemens Medical Solutions; Forchheim, Germany) revealed a U-shaped HSK. On contrast-enhanced CT, the HSK and its relation with the aorta and inferior vena cava (IVC) were carefully examined. The IVC was situated to the right side of the AA. It received the right renal vein before merging with the left renal vein to form the subhepatic IVC. There were asymmetric paired renal veins that drained the HSK. The CT images also revealed the left renal vein compression with proximal distention without the presence of collateral pathways between the superior mesenteric artery and the AA (fig. 1a). The HSK was vascularized by normally positioned small right and left RAs, and a significant aberrant RA originating 

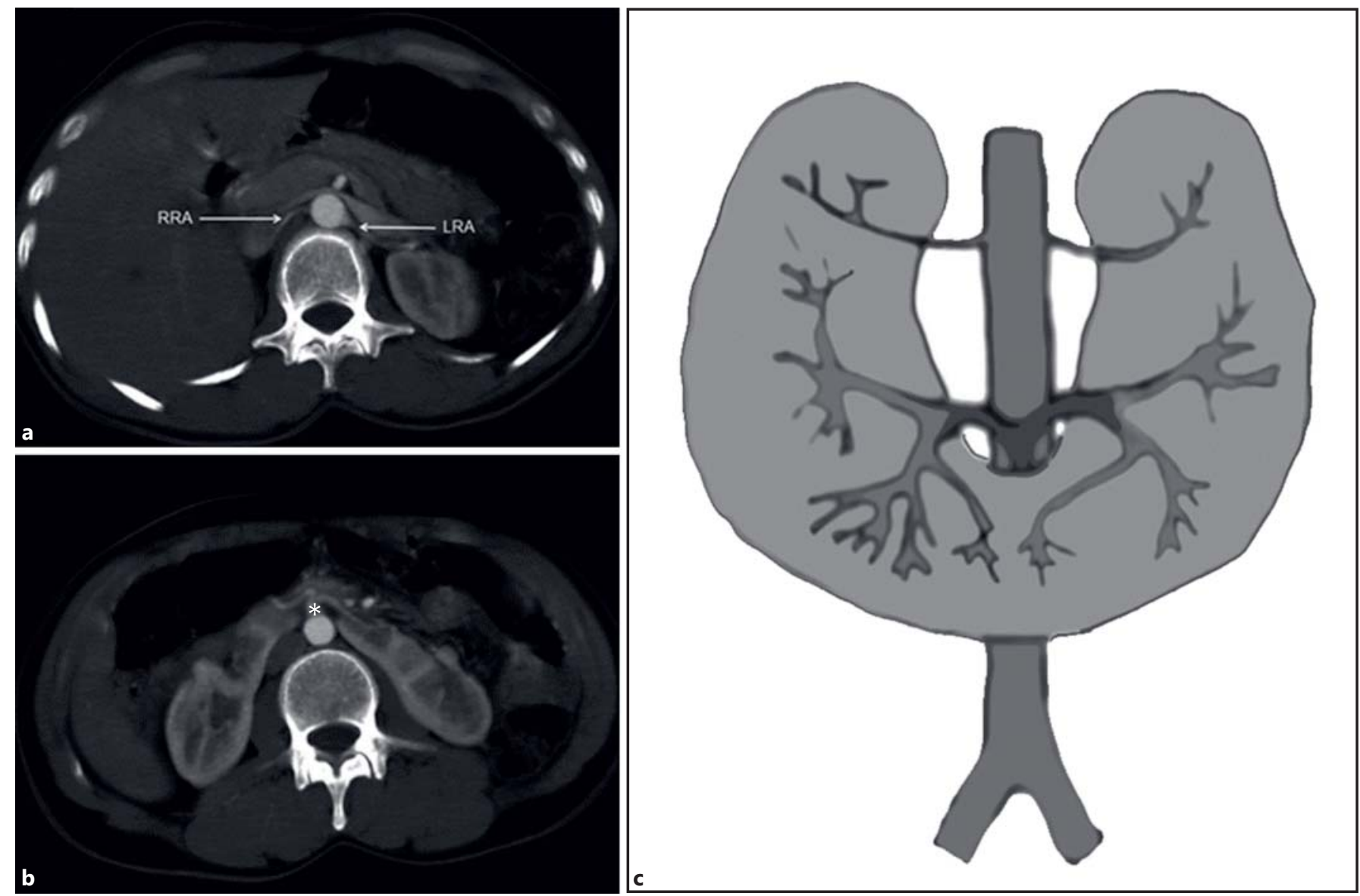

The CT image shows a single large aberrant RA (asterisk) originat

Fig. 1. a MIP axial view of the RAs. The CT image shows both RAs (arrows) with low calibration arising from the proximal AA. The image also reveals an anomaly known as the nutcracker syndrome between the superior mesenteric artery and the AA. RRA = Right RA; LRA = left RA. b MIP axial view of the variant isthmic artery.

from the distal AA (fig. 1a, b). The aberrant artery divided into two branches from a trunk, supplying the isthmus, lower lobes and middle portion of the HSK. The largest diameter of the main and aberrant RAs was measured within $5 \mathrm{~mm}$ of the ostium. The mean diameter of the right RA was $2.4 \mathrm{~mm}$ and of the left RA was $2.7 \mathrm{~mm}$. The mean diameter of the aberrant RA was $5.8 \mathrm{~mm}$.

\section{Discussion}

In this case the left renal vein compression was unusual and the CT examination provided good delineation of vascular and urinary tract anomalies. Nutcracker syndrome associated with renal fusion anomalies is uncommon. In a previously reported case, Pupca et al. [5] demonstrated multidetector-row CT angiography findings of

double nutcracker syndrome in a patient with cross-fused renal ectopia. They identified a left cross-fused renal ectopia, L-shaped type, with four RAs, two left renal veins, and also demonstrated the compression of the upper renal parenchyma vein in the aortomesenteric angle, and the compression of the lower renal parenchyma vein between the AA and the L2 vertebral body. Unlike their case, our patient had the HSK anomaly from which the most common type of renal fusion occurs. Furthermore, we demonstrated the compression of the left renal vein between the AA and the L2 vertebral body together with three RAs and two renal veins.

In another study, Eisendrath et al. [3] described two arteries for each half and one for the isthmus in patients with HSK. According to the authors, there was an aortic branch for the isthmus in this definition. In another 
study, Crawford et al. [6] made a similar classification of the arterial supply in patients with HSK. The arterial supply of the present case did not resemble any type of the Graves classification. On the other hand, our case presented a different side from either of the classifications from the two studies mentioned above. On these classifications, the common isthmic trunk had a low calibration and two arteries for each half had a normal calibration. In a study conducted by the Turba et al. [7] to determine renal arterial anatomy and gender differences in adults without renovascular disease using multidetector CT angiography, the authors found that the mean diameter of all right RAs was $4.82 \mathrm{~mm}$ and of all left RAs was $4.89 \mathrm{~mm}$. In our case, both RAs originating from the AA were rudimentary and the HSK accompanied the nutcracker syndrome. Therefore, an unusual case of a large single isthmic artery supplying a large part of the HSK was described, which was an incidental finding. There were bilateral normally located RAs but both vessel diameters were very thin (right RA $2.4 \mathrm{~mm}$, left RA $2.7 \mathrm{~mm}$ ). These thin vessels only supplied the upper parts of the HSK. However, the common isthmic trunk which originated distal from the AA was fairly thick $(5.8 \mathrm{~mm})$ and also supplied the middle and lower parts of the HSK (fig. 1c). The distance of the superior mesenteric artery and the AA had diminished, promoting a dilatation before the stenosis segment of the left renal vein, which is known as the nutcracker syndrome. To our knowledge this coexistence represents a unique case defined in the English literature.

The left renal vein normally lies anterior to the AA. The compression of the left renal vein between the superior mesenteric artery and the AA produces the nutcracker syndrome with the increased pressure in the left renal vein leading to congestion of the left kidney and the venous communications. A case in which compression is seen on radiologic images but there is no clinical mani- festation is known as the nutcracker phenomenon. In our case, the compression of the left renal vein was an incidental finding. Nutcracker syndrome is most commonly seen in relatively healthy females in the third or fourth decade of life. It is manifested by left flank pain, with or without unilateral hematuria or proteinuria [8].

Doppler ultrasonography, magnetic resonance angiography and CT angiography are the noninvasive methods of choice for the assessment of the vessels and lesions of the HSK. These imaging techniques also provide useful information about associated pathological conditions and variant arterial supply. Multiplanar reconstruction, maximum intensity projection (MIP) and three-dimensional volume rendering images are the most commonly used multidetector CT angiography techniques for the assessment of the vasculature of the HSK [9]. With these CT angiography techniques, the location and course of the vessels can be precisely visualized as in our case. On the other hand, conventional or digital subtraction angiography also gives perfect visualization, sometimes superior to CT angiography.

The HSK usually does not require surgical treatment because it is almost always asymptomatic. However, in a situation when surgery is needed for other reasons (e.g. aortic surgery due to aneurysmal or occlusive disease), recognizing variations in renal supply is of ultimate importance $[6,10]$.

\section{Conclusion}

In this patient with HSK, the left renal vein compression was unusual and the CT examination provided a good delineation of the vascular and urinary tract anomalies. Being unaware of the arterial variations of HSK could lead to unfavorable results, especially in cases in which surgery is planned in this region.

\section{References}

-1 Natsis K, Piagkou M, Skotsimara A, et al: Horseshoe kidney: review of anatomy and pathology. Surg Radiol Anat 2014;36:517-526.

2 Graves FT: Arterial anatomy of congenitally abnormal kidney. Brit J Surg 1969;56:533541.

-3 Eisendrath DN, Phifer FM, Culver HB: Horseshoe kidney. Ann Surg 1925;82:735764.

4 Koplay M, Onbas O, Alper F, et al: Multiple renal arteries: variations demonstrated by multidetector computed tomography angiography. Med Princ Pract 2010;19:412-414.
-5 Pupca G, Miclăuş GD, Bucuraş V, et al: Left crossed fused renal ectopia L-shaped kidney type, with double nutcracker syndrome (anterior and posterior). Rom J Morphol Embryol 2014;55:1237-1241.

-6 Crawford ES, Coselli CS, Safi HJ, et al: The impact of renal fusion and ectopia on aortic surgery. J Vasc Surg 1988;8:375-383.

7 Turba UC, Uflacker R, Bozlar U, Hagspiel KD: Normal renal arterial anatomy assessed by multidetector CT angiography: are there differences between men and women? Clin Anat 2009;22:236-242. $\checkmark 8$ Rudloff U, Holmes RJ, Prem JT, et al: Mesoaortic compression of the left renal vein (nutcracker syndrome): case reports and review of the literature. Ann Vasc Surg 2006;20:120 129.

9 O'Brien J, Buckley O, Doody O, et al: Imaging of horseshoe kidneys and their complications. J Med Imaging Radiat Oncol 2008;52:216226.

10 Demirer Z, Zor M, Kurt B, et al: Bilateral renal metastasis of an inguinal malignant solitary fibrous tumor, 9 years after primary surgical treatment. Med Princ Pract 2012;21:585-587. 